\title{
Evaluation of Mungbean Mutant Lines to Drought Stress and Their Genetic Relationships Using SSR Markers
}

\author{
Yuliasti $^{\star 1}$ and Reflinur ${ }^{2}$ \\ ${ }^{I}$ Center for Isotopes and Radiation Application, National Nuclear Energy Agency \\ Jl. Lebak Bulus Raya No. 49, Jakarta 12440, Indonesia \\ ${ }^{2}$ Indonesian Center for Agricultural Biotechnology and Genetic Resources Research and Development \\ Jl. Tentara Pelajar No. 3A, Bogor, West Java, Indonesia
}

\section{ARTICLE INFO}

Article history:

Received 04 October 2014

Received in revised form 04 June 2015

Accepted 16 June 2015

Keywords:

Mungbean

Mutant

Drought tolerance

Genetic variation

SSR markers

\begin{abstract}
A B S T R A C T
Development of mungbean cultivars tolerant to drought stress through mutation breeding approach would enable us to anticipate the crop yield-reducing effects of climate changes. The objective of this research was to evaluate the yield performance of mungbean mutant lines that showed tolerance to drought stress, and to analyze their genetic diversity and relationship among mutant lines using SSR markers. The study was conducted during the dry season of 2012 in the Muneng experimental farm, Probolinggo, East Java. The experiment was laid out in a randomized block design with four replications. Five mutant lines and two parental lines as control were tested for evaluation of yield and drought tolerance under two environments of two irrigation systems as treatment. The two environmental conditions consisted of optimal irrigation (at least three times: at planting, flowering and during pod filling) and suboptimal irrigation (two times at planting and flowering). To evaluate genetic variation among selected mutant lines and their discrimination from parental lines in molecular level, a cluster analysis was performed using Unweighted Pair Group Method with Arithmetic Mean (UPGMA) in the NTSYS software. The results showed that three mutant lines, including PsJ30, PsJ31, PsJ32 produced the highest grain yields of 1.17, 1.01, and 1.04 ton/ha, respectively, compared to the other mutant lines and the parents Gelatik $(0.85$ ton/ha) and Perkutut $(0.87$ ton/ha) as control check. Of those mutant lines, PSJ31 was the most tolerant to drought with sensitivity index value of 0.47 . The PSJ31 has now been officially released as a new variety ( 2013), named as Muri which was identified to have high yield and tolerant to drought. Based on 23 SSR markers used for clustering analysis of those 3 selected mutant lines, 9 SSR markers (MBSS R033; satt137; MBSSR008; MBSSR203; MBSSR013; MBSSR021; MBSSR016; MBSSR136; and DMBSSR013) were successfully identified the three mungbean mutant lines. Taken together, we have succeeded at develop and evaluate three elite mutant breeding lines which are valuable resources for genetic variation in mungbean. The genetic variation information of mungbean at molecular level potentially provides room for recombinants which are essential for the development of a new superior variety in mungbean improvement.
\end{abstract}

(C2015 Atom Indonesia. All rights reserved

\section{INTRODUCTION}

Pulses are an integral part of Indonesian agriculture. Among the pulse crops, mungbean

${ }^{*}$ Corresponding author.

E-mail address: yuliasti@batan.go.id

DOI: http://dx.doi.org/10.17146/aij.2015.412
(Vigna radiata L.), the third pulse crop of Indonesian, has a special importance in intensive crop production of the country for its short growing period, wide adaptability, low input requirements, and ability to improve the soil by fixing atmospheric nitrogen. This crop contains $51 \%$ carbohydrate, $24-26 \%$ protein, $4 \%$ mineral, and $3 \%$ vitamins [1]. The yield of grain legume or pulse is less than the 
yields of most of cereals. The low productivity of the pulses may be attributed to their susceptibility to pathogenic microorganisms, asynchronous habit of pod maturity, shedding of flowers/newly-formed pods, and indeterminate and long duration of growth, all resulting in low seed yield per plant. In Indonesia, mungbean production is expected to increase significantly. However, the yield of mungbean is still low, averaging approximately 0.7 tons of dry grains per hectare, while the average potential yield of superior mungbean is only 1.20-1.75 tons dry grains per ha. The cultivation of mungbean in arid areas which face droughts and are poor in soil nutrients is one of the main reasons for the low yield of mungbean. Development of mungbean is a cheap solution to resolve the issue. A challenge of mungbean development in the arid area is how to increase the productivity and maintain the quality of land to sustain production. However, mungbean can be viewed as an alternative commodity to be developed in such areas, especially those cultivars with low harvest indices. Drought is a worldwide problem, seriously constraining global crop production and quality. Moreover, recent global climate change has made this situation becomes more serious. Breeding and developing new crop varieties adapted to climate change is one of the important strategies for adapting agriculture to the changing environments. Increase in drought periods may require the development of drought tolerant crops $[2,3]$.

Previous studies have demonstrated that drought stresses eventually result in a wide series of biochemical and physiological modifications [4]. Induced mutation has played a vital role in altering the genetic makeup of genotypes, not merely at chromosomal level, but also at molecular level [5]. Mutation breeding is probably an effective tool for generating variability in the existing varieties and selecting desirable characters lines which proved to be an ideal crop for abiotic stress. This technique has been widely used in efforts to breed abiotic stress tolerance with some success [6,7]. An intensive mungbean breeding effort in the Center for the Application of Isotopes and Radiation Technology, Indonesian National Nuclear Energy Agency (PATIR-BATAN), began in 1975 by mutation breeding, resulting in the release of Camar 1991 and Muri varieties 2013 which exhibited higher yields and tolerance to drought. Genetic relationships analysis among accessions are helpful for designing future breeding efforts for yield, quality, and pest resistance improvement [8]. In addition, evaluation of genetic diversity is also very important for crop plant genetic resources [9].
DNA-based molecular markers such as simple sequence repeats (SSRs), a short tandem repetitive DNA sequences with a repeat length of a few (one to five) base pairs [10], [11] and single nucleotide polymorphisms (SNPs) have been proven as powerful tools in studying the genetic diversity and population structure of species. Due to their advantages, such as co-dominance and high polymorphism, SSRs or microsatellite markers are particularly attractive for studying genetic structures and the relationships between species [12]. These markers have become a good choice for a wide range of applications such as genetic mapping and genome analysis, genotype identification and variety protection, seed purity evaluation and germplasm conservation, diversity studies, paternity determination and pedigree analysis, gene and quantitative trait locus analysis, and marker-assisted breeding. SSR markers were used to analyze the genetic diversity of 30 mungbean mutant lines along with its parent [13].

SSR has a higher resolving power for detecting population structure and estimating genetic diversity than SNP in a sample of 303 accessions of domesticated soybean and its wild progenitor Glycine soja [14]. SSRs have been used successfully in estimation of genetic diversity and relationships in sorgum genotypes for drought tolerance [15]. The genetic relationships among mutant lines are helpful for designing future breeding efforts for yield, quality and pest resistance improvement [16]. New molecular breeding strategies such as markerassisted recurrent selection (MARS) and genomic selection (GS) or genome-wide selection (GWS) are discussed as options to be integrated in crop improvement programmes for developing the next generation of drought-tolerant crops [17]. Detection of polymorphism between the parents by SSRs microsattelite markers usefulness in diversity analys is, mapping agronomically important traits and marker assisted breeding in mungbean [18]

The paucity of polymorphic molecular markers in mungbean has been a limiting factor in application of molecular tools for its genetic improvement. In the present study, a total of 23 SSR markers were used for clustering analysis of the three selected mutant lines, of which nine markers were able to discriminate the mutant lines.

The objectives of the present study were to evaluate yield performance of the mungbean mutant lines, to evaluate their tolerance to drought stress, and to analyze the genetic diversity and relationship among mutant lines using SSR markers. 


\section{EXPERIMENTAL METHODS}

\section{Plant materials}

A total of nine mungbean mutant lines were used in this study. These mutant lines were derived from induced mutations through gamma irradiation performed at the Center for the Application of Isotopes and Radiation Technology at BATAN. The yield of these mutant lines under both normal and drought stress conditions were tested to select a promising mungbean mutant line tolerant to drought stress with high yield. The two control varieties, including the Gelatik and the Perkutut, were included in this study. The selected mutant lines which showed high yields and tolerance to drought and were then subjected to molecular analysis using SSR markers in order to discriminate the selected mutant lines from the parental lines and to detect variation among selected mutant lines at molecular level

\section{Field experiment}

The evaluation of the response of the mutant mungbean lines to drought stress was conducted in the Muneng experimental farm, Probolinggo, East Java, during the dry season of 2012. Nine mutant mungbean lines, and the two check varieties (Gelatik and Perkutut) as control, were grown in the field experiment. The experiment was conducted under a randomized completely block design (RCBD) with four replications and two environments consisted of optimal irrigation (at least three times: at planting, at flowering, and during pod filling) and suboptimal irrigation (two times at planting and flowering). The growth and yield of the selected drought-tolerant plants were evaluated in the field condition.

\section{Molecular analysis}

\section{DNA extraction and SSR analysis}

Five mutant lines showing high yields under drought conditions were selected and subjected to molecular analysis. DNA was extracted from young leaves using the standard cetyltrimethylammonium bromide (CTAB) method [19]. The concentrations of the DNA samples were determined with a spectrophotometer, and the DNA samples were diluted to $50 \mathrm{ng} / \mu \mathrm{l}$ for analysis using SSR markers. A total 23 SSR primers derived from mungbean [20] and soybean sequences [21] were used in this study. PCR analysis was conducted in a volume of
$15 \mu \mathrm{l}$ which contained $20 \mathrm{ng} / \mu \mathrm{l}$ of genomic DNA, $0.25 \mu \mathrm{M}$ of each primer (forward and reverse), $0.125 \mathrm{mM}$ of each dNTP, 0.15 units of TaqDNA polymerase, and $1 \times$ reaction buffer. The PCR amplification was performed in a thermal cycler and consisted of an initial denaturation step of $3 \mathrm{~min}$ at $94^{\circ} \mathrm{C}$, followed by 35 cycles at $94{ }^{\circ} \mathrm{C}$ for $45 \mathrm{~s}, 47$ to $57^{\circ} \mathrm{C}$ (depending upon the primer pair) for $30 \mathrm{sec}$, $72^{\circ} \mathrm{C}$ for $1 \mathrm{~min}$, and 1 cycle of $72^{\circ} \mathrm{C}$ for $10 \mathrm{~min}$. PCR products were separated on $6 \%(\mathrm{w} / \mathrm{v})$ nondenaturation polyacrylamide gel and visualized by ethidium bromide. The ethidium bromide stained gels were documented using chemidoc (Biorad, USA).

\section{Data analysis}

Combined analysis of variance based on Random Complete Block Design (RCBD) and comparison of quantitative traits means based on Duncan's new multiple range test (DNMRT) were performed in [22].

Drought tolerance was measured using drought sensitivity index (S) as described by [23]. In summary, $S=(1-\mathrm{Y} / \mathrm{Yp}) /(1-\mathrm{X} / \mathrm{Xp})$, where $(\mathrm{Y})=$ average of pod number, pod dry weight, root length, root dry weight of a drought-treated genotype; $(\mathrm{Yp})=$ average of variables of optimally grown genotype; $(\mathrm{X})=$ variable values of all drought-treated genotypes; and $(\mathrm{Xp})=$ variable values of all optimally grown genotype. Plants are classified as tolerant if having sensitivity index of $<0.5$, moderately tolerant if $0.5<\mathrm{S}<1$, and sensitive if $\mathrm{S}>1$.

PCR products amplified by SSR markers were scored visually for their presence (1) or absence (0). To measure the informativeness of the markers, the polymorphism information content (PIC) for each SSR locus was calculated according to the formula [24]: PIC $=1-(\Sigma \mathrm{pi} 2)$, where, $\mathrm{i}$ is the total number of alleles detected for a SSR marker, and pi is the frequency of the ith allele in the set of the 20 genotypes investigated. A dendrogram was constructed based on Jaccard similarity coefficient with unweighted pair group method and arithmetic average (UPGMA) using the NTSYS-pc version 2.02 [25].

\section{RESULTS AND DISCUSSION}

The data on mungbean yield was subjected to statistical analysis and significant differences were found among the mutant lines and control plant under drought condition (Table 1). The grain yield of mungbean crop is a function of cumulative effect 
of various yield components, which are influenced by the genetic make-up of variety, various agronomic practices, and environmental conditions. Table 1 also shows that mungbean could grow better and yield more under drought condition than the varieties already in cultivation. PSj S31 produced grain yield 1.17 ton $\mathrm{ha}^{-1}$. These yields were significantly higher compared to their original varieties Gelatik (0.85 ton $\left.\mathrm{ha}^{-1}\right)$ and the national check variety, Perkutut $\left(0.87\right.$ ton ha $\left.{ }^{-1}\right)$, under drought condition (Table 1).

Table 1. Yield performance of mungbean mutant lines under two drought envinronment conditions

\begin{tabular}{lcc}
\hline \multirow{2}{*}{$\begin{array}{c}\text { Mutant lines } \\
\text { /Variety }\end{array}$} & \multicolumn{2}{c}{ Yield (t/ha) } \\
\cline { 2 - 3 } & Optimal Condition & Drought Condition \\
\hline PsJ S-30 & $1.25 \mathrm{~d}$ & $1.17 \mathrm{e}$ \\
PsJ S- 31 & $\mathbf{1 . 5 3 ~ b}$ & $\mathbf{1 . 0 1} \mathbf{~ f}$ \\
PsJ S-32 & $1.46 \mathrm{bc}$ & $1.04 \mathrm{f}$ \\
PsJ-6 & $1.31 \mathrm{~d}$ & $0.95 \mathrm{~g}$ \\
PsJ-19 & $1.49 \mathrm{bc}$ & $1.00 \mathrm{fg}$ \\
PsJ-21 & $1.58 \mathrm{~b}$ & $0.95 \mathrm{~g}$ \\
PsJ-BII-17 & $1.71 \mathrm{a}$ & $0.96 \mathrm{~g}$ \\
PsJ-BII-5 & $1.37 \mathrm{c}$ & $0.95 \mathrm{~g}$ \\
PsJ-BII-15 & $1.35 \mathrm{c}$ & $1.01 \mathrm{f}$ \\
Gelatik & $1.31 \mathrm{~d}$ & $0.85 \mathrm{~h}$ \\
Perkutut & $1.35 \mathrm{c}$ & $0.87 \mathrm{~h}$ \\
Rerata (t/ha) & $\mathbf{1 . 4 2}$ & $\mathbf{0 . 9 7}$ \\
CV 5\% & $\mathbf{1 5 . 2 5}$ & \\
\hline
\end{tabular}

Notes: Values followed by same letters with in a row are found not significantly different by Duncan Multiple Range Test $(\mathrm{P}, 0.05)$

The highest yielding was related to PSj S31 mungbean mutant lines. Under drought conditions mutant line PSj S31 had the best grain yield compared to the parent (Gelatik) (Table 1). In semilar to our result [26] found that maximum production of maize was recorded for normal irrigation as 7 day irrigation period and application of mycorrhiza and Zn chelate, while severe water stress and non application of mycorrhiza and $\mathrm{Zn}$ chelate produced minimum production. Considering weight and pods number plant-1 is one of the major components of grain yield, the superiority of seed weight and pods number plant-1 is important in plant breeding to improve grain yield [27]. From these data it could be concluded that the mutant line PSj S31 is a promising line to be developed as dual purpose mungbean, as grain especially when grown in dry land. The mutants are candidates for new high yield varieties tolerant to drought.
Table 2. Sensitivity index values of mungbean mutant lines under drought condition

\begin{tabular}{|c|c|c|c|c|c|c|}
\hline \multirow[b]{2}{*}{$\begin{array}{c}\text { Mutant lines/ } \\
\text { Varieties }\end{array}$} & \multicolumn{6}{|c|}{ Sensitivity index } \\
\hline & $\begin{array}{c}100- \\
\text { grain } \\
\text { weight }\end{array}$ & $\begin{array}{c}\text { Res } \\
\text { pon } \\
\text { se }\end{array}$ & $\begin{array}{c}\text { Grain } \\
\text { dry } \\
\text { weight }\end{array}$ & $\begin{array}{l}\text { Res } \\
\text { pon } \\
\text { se }\end{array}$ & $\begin{array}{c}\text { Root dry } \\
\text { weight }\end{array}$ & $\begin{array}{c}\text { Respo } \\
\text { nse }\end{array}$ \\
\hline PsJ S-30 & -0.395 & $\mathrm{~T}$ & 1.100 & $\mathrm{TL}$ & 1.032 & $\mathrm{TL}$ \\
\hline PsJ S- 31 & 0.214 & $\mathbf{T}$ & 0.468 & $\mathbf{T}$ & -0.003 & $\mathbf{T}$ \\
\hline PsJ S-32 & -3.253 & $\mathrm{~T}$ & 0.839 & MTL & 0.337 & TL \\
\hline PsJ-6 & 0.627 & MTL & 0.793 & MTL & 0.527 & TL \\
\hline PsJ-19 & -1.970 & $\mathrm{TL}$ & 1.027 & $\mathrm{TL}$ & 1.229 & $\mathrm{TL}$ \\
\hline PsJ-21 & 1.559 & $\mathrm{TL}$ & 1.371 & TL & 0.926 & $\mathrm{TL}$ \\
\hline PsJ-B11-17 & 2.166 & $\mathrm{TL}$ & 1.605 & $\mathrm{TL}$ & 1.568 & $\mathrm{TL}$ \\
\hline PsJ-BII-5 & 4.048 & TL & 0.916 & MTL & 2.158 & TL \\
\hline PsJ-BII-15 & 2.085 & TL & 0.678 & MTL & 1.335 & $\mathrm{TL}$ \\
\hline Gelatik & 2.314 & TL & 1.111 & $\mathrm{TL}$ & 0.872 & MTL \\
\hline Perkutut & 2.996 & $\mathrm{TL}$ & 0.996 & MTL & 0.737 & MTL \\
\hline \multicolumn{7}{|c|}{$=$ Tolerance $(\mathrm{T})$} \\
\hline \multicolumn{7}{|c|}{$=$ Moderately Tolerance (MTL) } \\
\hline
\end{tabular}

The sensitivity index data of mutants under drought condition are presented in Table 2. Based on calculation of sensitivity index (SI) value on 100-grain weight, grain dry weight, and root dry weight under drought condition, the PsJ S 31 mutant were classified as drought-tolerant mutant line with the value of $0.214 ; 0.468$ and -0.03 , respectively. The result showed that the control plants, the Gelatik and the Perkutut, were categorizable as sensitive to drought. The Gelatik had SI values of $2.314,1.111$, and 0.872 of 100 -grain weight, grain dry weight, and root dry weight, respectively, whereas the SI value for 100-grain weight, grain dry weight, and root dry weight observed for the Perkutut cultivar were 2.996, 0.996, and 0773, respectively. Overall, the relatively high drought tolerance plant was observed in the PsJ S31 line, as indicated by its low sensitivity index values. This low sensitve index $<0.5$ indicates that these mutant lines were more tolerant to the condition of drought with regard to the ability of producing grain yield. In other words, their grain yield production was reduced by less than $30 \%$ under drought condition. The PsJ S 31 mutant line is described by BATAN as highly tolerant to drought stress compared to the parental lines Glatik and Perkutut national control variety. Stresses, especially in the growing stage, reduces the capacity of the source plants for the source and sink is forced to balance the number of flowers and pod production to reduce the stress which has to be handled during the grain-filling period; this also reduced the final yield. The results of this study are in agreement with [28] which reported that moisture stress reduces grain yield of mungbean 
and maximum negative effects of drought obtained with once irrigation during growth season also obtain ed the similar results [29].

\section{SSR analysis}

SSR evaluations carried out in present study could be useful to determine the variation among mutant lines and to discriminate mutants from the wild type in molecular level. Of the total of 23 SSR primers used in discriminating of 3 selected mungbean mutants and the parental lines, 12 primers exhibited polymorphism (Table 3) lines.

Table 3. Summary statistics of 12 polymorphic SSR primers genotyped on mungbean mutant lines

\begin{tabular}{lccccc}
\hline SSR primer & $\begin{array}{c}\text { Major.Allele. } \\
\text { Frquency }\end{array}$ & $\begin{array}{c}\text { Allele } \\
\text { No }\end{array}$ & GeneDiversity Heterozygosity & PIC \\
\hline MBSSR033 & 0.3750 & 4.0000 & 0.6875 & 1.0000 & 0.6299 \\
MBSSR086 & 0.5000 & 3.0000 & 0.6250 & 1.0000 & 0.5547 \\
Satt137 & 0.7500 & 2.0000 & 0.3750 & 0.5000 & 0.3047 \\
MBSSR008 & 0.7500 & 2.0000 & 0.3750 & 0.0000 & 0.3047 \\
MBSSR063 & 0.5000 & 2.0000 & 0.5000 & 1.0000 & 0.3750 \\
MBSSR203 & 0.7500 & 2.0000 & 0.3750 & 0.5000 & 0.3047 \\
Gaat47 & 0.5000 & 2.0000 & 0.5000 & 1.0000 & 0.3750 \\
Gat216 & 0.5000 & 2.0000 & 0.5000 & 1.0000 & 0.3750 \\
DMBSSR013 & 0.8750 & 2.0000 & 0.2188 & 0.2500 & 0.1948 \\
DMBSSR021 & 0.8750 & 2.0000 & 0.2188 & 0.2500 & 0.1948 \\
DMBSSR016 & 0.8750 & 2.0000 & 0.2188 & 0.2500 & 0.1948 \\
DMBSSR136 & 0.7500 & 3.0000 & 0.4063 & 0.5000 & 0.3706 \\
Mean & 0.6667 & 2.3333 & 0.4167 & 0.6042 & 0.3482 \\
\hline & & & & & \\
\hline
\end{tabular}

A total of 28 alleles were detected with an average alleles per locus of 0.85 , ranging from 2 to 4. The PIC value, reflecting allele diversity for a particular marker, ranged from 0.19 (DMBSSR013, DMBSSR016, and DMBSSR021) to 0.63 (MBSSR033) with an average of 0.35 . The diversity index for the 12-marker set was in the range of $0.21-0.69$ with an average of 0.42 . The mean PIC value and diversity index were indicative of low levels of genetic diversity in the tested mutant mungbean lines.

Based on UPGMA cluster analysis, those mungbean mutant lines were clearly different from the wild type in which they were grouped into two clusters, and two outliers (Fig. 2).

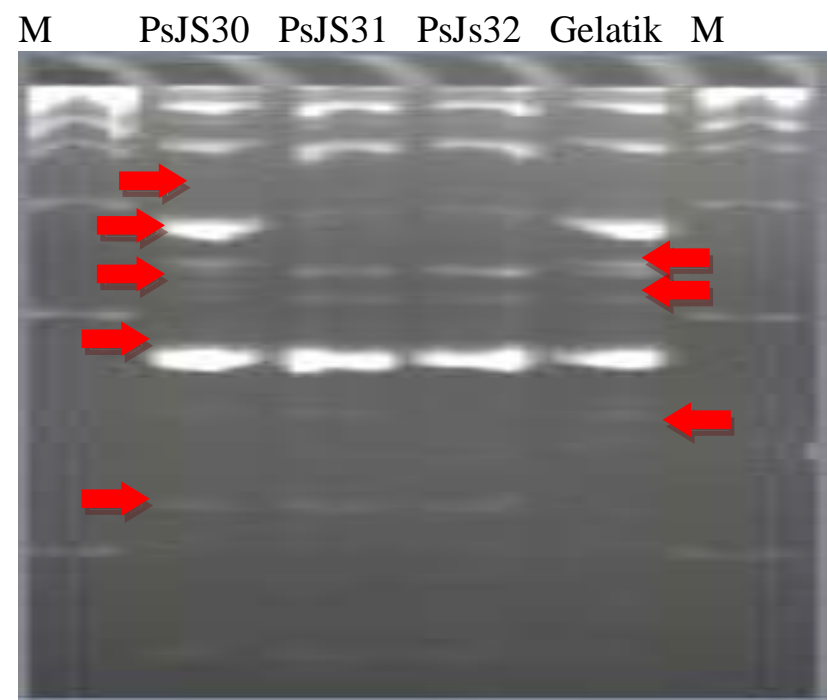

Fig. 1. SSR profile of mungbean mutant lines amplified by MBSSR086 \{ MB1, MB2, MB3, M10 MB1= Mungbean Mutant 1, MB2= Mungbean Mutant 2; MB3= Mungbean Mutan 3, MB10= wild type Lanes M, 100 bp.

The major cluster I was of the wild type, while cluster II contained mutant lines which were separately grouped into cluster I. 2 outliers. Of the 23 SSR markers used in clustering, 9 SSR markers (MBSSR033, satt137, MBSSR008, MBSSR203, MBSSR013, MBSSR021, MBSSR016, MBSSR136, and DMBSSR013) were successfully identified. The results of this study are in agreement with [15], SSR primer MB122A was identified as the best primer for mutant analysis and the SSR markers could be utilized well to analyze the mutants at DNA level.

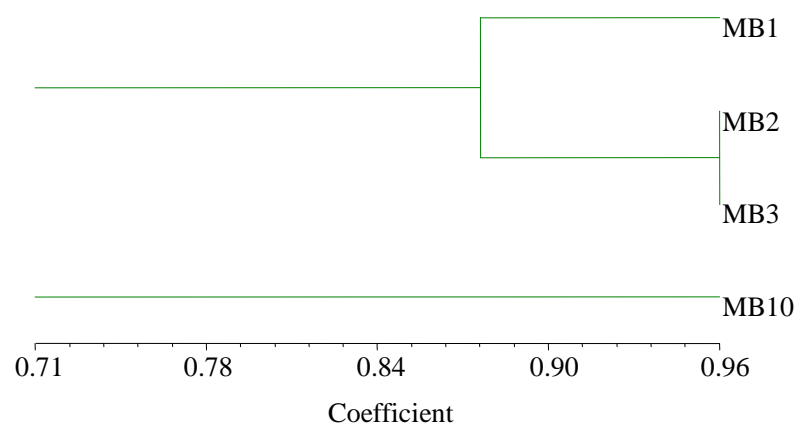

Fig. 2. Dendrogram of mungbean mutant lines based on an unweighted pair group mean average (UPGMA) cluster analysis using the Jaccard's similarity coefficient three mungbean mutant lines.

SSR primers were chosen as DNA markers in the present study because they produced multiple bands for one or more accession. These multiple bands may be due to annealing at more than one locus or duplication of primer binding sites in the cross-species legumes. This indicates a high level of 
sequence conservation among the flanking regions of microsatellites. This sequence conservation formed the basis of cross-species utilization of SSR primers in assessing the phylogenetic relationships across species and genera.

\section{CONCLUSION}

The present study was able to evaluate the performance of mutant mungbean lines under drought environment condition. Further, three elite mutant breeding lines were selected for their tolerance to drought and high yield. These mutant lines are promising lines which provide valuable resources for genetic variation to enhance the mungbean breeding program in Indonesia.

Through selection processes and direct screening for drought tolerance, the number of potential mutant lines has been obtained. In the dry season, the mutant PSj S 31 attained a significantly higher grain yield than the original variety, the Gelatik. These mutant lines were officially released in 2013 as new mungbean varieties tolerant to drought.

\section{ACKNOWLEDGEMENT}

Financial supports from PATIR BATAN are greatly appreciated. The authors thank the Ministry of research and Technology for including mungbean in the grant program 2009-2011.

\section{REFERENCES}

1. M.M.A. Mondal, A.B. Puteh, M.A. Malek et al., Scientific World Journal (2012) 425168.

2. M. Ahmed, M. Asif, M. Sajad et al., Aust. J. Crop Sci. 7 (2013) 1642.

3. S. Ceccarelli, S. Grando, M. Maatougui et al., J. Agric. Sci. 148 (2010) 627.

4. G. Garg, J. Environ. Biol. 31 (2010) 261.

5. H.S. Alan, Euphytica 158 ( 2007) 313.

6. J. Gai, Y. Liu, H. Lu et al., Identification of Mutants with Tolerance Torhizospheric Stresses and Inheritance and QTL Mapping of Related Root Traits in Soybean, Mutational Analysis of Root Characters in Food Plants, Proceedings of a Final Research Coordination Meeting Organized by the Joint FAO/IAEA
Programme of Nuclear Techniques in Food and Agriculture (2006) 43.

7. M.H. Spreeth and J.A. De Ronde, Development and Evaluation of Drought Resistant Mutant Germplasm of Vigna Unguiculata and Vigna Subterranea Agricultural Research Council, Roodeplaat Vegetable and Ornamental Plant Institute, Pretoria, South Africa, Proceedings of a final Research Coordination Meeting Organized by the Joint FAO/IAEA Programme of Nuclear Techniques in Food and Agriculture (2006) 97.

8. L. Wang, R. Guan, L. Zhangxiong et al., Crop. Sci. 46 (2006) 1032.

9. M.P. Chapuis and Estoup, Molecular Biology Evolution 24 (2007) 621.

10. C. Lung'aho, G. Chemining'wa, Y.B. Fu et al., American Journal of Potato Research $\mathbf{8 8}$ (2011) 424.

11. M.W. Ganal, T. Altmann and M.S. Röder, Current Opinion in Plant Biolog. 12 (2009) 211.

12. R.K. Saxena, K.B. Saxena, R.V. Kumar et al., Plant Breeding 129 (2010) 135.

13. S.K.S Ingh, G.R. Alavanya, K.V. Bhat et al., Indian Hill Farming 25 (2012) 38.

14. Y-H. Li, W. Li, C. Zhang et al., New Phytologist Trust 188 (2010) 242.

15. K. Rajarajan and K. Anesamurthy, Indian Journal of Genetics 71 (2011) 17.

16. P. Tantasawat, J. Trongchuen, T. Prajongjai et al., AJCS 5 (2011) 283.

17. R. Rouf Mir, M. Zaman-Allah, N. Sreenivasulu et al., Theoretical and Applied Genetics 125 (2012) 625.

18. A. Farnia and S. Khodabandehloo, International Journal of Life Sciences 9 (2015) 75.

19. J. Chen, W. Xu, J. Velten et al., Soil and Water Conservation 67 ( 2012) 354.

20. P. Somta, W. Seehalak and Srinives, Springer Science+Business Media B.V., Conserv Genet 10 (2009) 1939.

21. H. Hisano, S. Sato, S. Isobe et al., DNA Research 6 ( 2007) 257.

22. Anonymous, SAS User's Guide Version 8 , SAS Institute Inc., NC. (1999).

23. R.A. Fischer and R. Maurer, Agricultural Research 29 (1978) 897. 
24. B.S. Weir, Genetic Data Analysis II Methods for Discrete Population Genetic Data, Sinauer Associates Inc., Sunderland, Massachusetts, (1996) 377.

25. F.J. Rohlf, NTSYSpc Numerical Taxonomy and Multivariate Analysis System Version 2.1 User Guide, Applied Biostatistics Inc., New York (2000).

26. M. Nabizade, T.S. Nejad and M. Mojadam,
Journal of American Science 7 (2011) 86.

27. A.A. Lalinia, N.M. Hoseini, M. Galostian et al., International J. of Agronomy and Plant Production 3 (2012) 599.

28. M. Zare, B. Dehghani, O. Alizadeh et al., International Journal of Farming and Allied Sciences 2 (2013) 764.

29. M. Rafiei, Shirvan and M.R. Asgharipur, J. Mod. Agriculture Knowledge 5 (2009) 67. 